\title{
Avaliação do teor e composição do óleo essencial de Cymbopogon nardus (L.) em diferentes épocas de colheita ${ }^{1}$
}

\author{
Evaluation of content and composition of the essential oil of Cymbopogon nardus \\ (L.) in different harvest times
}

\author{
Henrique Guilhon de Castro ${ }^{2 *}$, Vilma Borges de Moura Perini ${ }^{3}$, Gil Rodrigues dos Santos $^{4}$ e Tarcísio Castro \\ Alves Barros Leal ${ }^{4}$
}

\begin{abstract}
Resumo - Este trabalho objetivou analisar o teor e a composição do óleo essencial do Cymbopogon nardus, em cinco épocas de colheita no Estado do Tocantins. As colheitas foram realizadas em cinco épocas em intervalos regulares de 28 dias, sendo a primeira aos 56 dias e a última aos 168 dias após transplante. A extração do óleo essencial foi realizada por hidrodestilação e a identificação dos componentes por CG e CG/EM. Os maiores teores de óleo essencial foram obtidos na segunda época de colheita $(1,10 \%)$ e na última época de colheita $(1,07 \%)$. Foram identificados vinte e três compostos químicos no óleo essencial. Os monoterpenos identificados foram: limoneno, linalol, isopulegol, citronelal, citronelol, neral, geraniol, acetato de citronelol e acetato de geraniol. Os sesquiterpenos identificados foram: beta-elemeno, germacreno, alfa-muroleno, gama-cadineno, delta-cadineno, elemol, germacreno D-4-OL, óxido de cariofileno, tau-cadinol, beta-eudesmol e alfa-eudesmol. Os compostos majoritários do óleo essencial foram o citronelol, o geraniol e o elemol.
\end{abstract}

Palavras-chave - Plantas medicinais. Capim citronela. Óleos essenciais. Época de colheita.

\begin{abstract}
This study aimed to analyze the content and the composition of the essential oil of Cymbopogon nardus in five harvest times in Tocantins State. Five harvesting were carried out in regular space of 28 days, the first in 56 days and the last in 168 days after transplanting. The essential oil was obtained by hydro distillation and the identification of the oil components by GC and GC/MS. The highest contents of the essential oil were obtained in the second harvest time (1.15\%) and in the last harvest time (1.07\%). Twenty three chemical compounds were identified in the essential oil. The monoterpenes identified were: limonene, linalool, isopulegol, citronellal, citronellol, neral, geraniol, citronellol acetate and geraniol acetate. The sesquiterpenes identified were: beta-elemene, germacrene, alpha-muurolene, gamma-cadinene, delta-cadinene, elemol, germacrene D-4-OL, caryophyllene oxide, tau-cadinol, beta-eudesmol, alpha-eudesmol. The main constituents of the essential oil were the citronellol, geraniol and elemol.
\end{abstract}

Key words - Medicinal plants. Citronella grass. Essential oil. Harvest time.

\footnotetext{
* Autor para correspondência

${ }^{1}$ Recebido para publicação em 04/02/2009; aprovado em 15/03/2010

Parte da dissertação apresentada pela segunda autora à Universidade Federal do Tocantins

${ }^{2}$ Engenharia Agronômica, Universidade Federal do Tocantins, Campus Universitário de Gurupi, Rua Badejós, Chácaras 69 e 72 , Lote 07, Caixa Postal 66, Gurupi-TO, Brasil, 77402-970, hguilhon@uft.edu.br

${ }^{3}$ Escola Estadual Setor Aeroporto, Secretaria da Educação do Estado do Tocantins, Gurupi-TO, Brasil, vilmaperini@hotmail.com

${ }^{4}$ Engenharia Agronômica, Universidade Federal do Tocantins, Gurupi-TO, Brasil, gilrsan@uft.edu.br
} 


\section{Introdução}

A determinação da época de colheita de plantas medicinais e aromáticas é essencial para obter maior teor de óleo essencial e melhor qualidade (CARVALHO FILHO et al., 2006). A colheita de plantas medicinais e aromáticas tem certas particularidades que a torna diferente das outras culturas, uma vez que objetiva conciliar a máxima produção de biomassa com maior (es) teor (es) de princípio(s) ativo(s) (BEZERRA et al., 2008).

$\mathrm{Na}$ obtenção da matéria-prima de plantas medicinais, as técnicas de cultivo devem atender ao objetivo de aumentar a produção de biomassa por área, sem comprometer o valor terapêutico da planta (CASTRO et al., 2004a). Neste aspecto, um fator crítico é a definição da época ideal de colheita, que deve proporcionar a coincidência entre os momentos de maior concentração do princípio ativo e de maior biomassa vegetal (COSTA et al., 2007).

A composição quantitativa e qualitativa dos metabólitos secundários das plantas é alterada acentuadamente durante as fases de crescimento. Sua produção varia de acordo com a idade das plantas, o estado reprodutivo, as opções metabólicas determinadas pelo efeito de hormônios com ciclos de síntese de substâncias influenciada pelas estações ou horas do dia e com as condições de cultivo (BROWN JÚNIOR, 1988; CASTRO et al., 1999; CASTRO et al., 2004b; LEAL et al., 2001).

Os óleos essenciais são misturas complexas e seus constituintes podem pertencer as mais diversas classes de compostos, porém os terpenos e os fenilpropenos são as classes de compostos mais comumente encontradas. Os terpenos encontrados com maior freqüência nos óleos essenciais são os monoterpenos e sesquiterpenos, bem como os diterpenos, constituintes minoritários dos óleos essenciais (CASTRO et al., 2004c; LOAYZA et al., 1995).

O capim citronela $(C$. nardus), planta originada da Índia, é utilizada na Indonésia como chá calmante e digestivo. O gênero Cymbopogon pertence à família Poaceae, subfamília Panicoideae. Este gênero é constituído de oitenta e cinco espécies (CASTRO et al., 2007).

O óleo essencial extraído de $C$. nardus possui alto teor de geraniol e citronelal. O citronelal é utilizado como material básico para a síntese de importantes compostos químicos denominados iononas e para a síntese de vitamina A. Esse óleo apresenta atividade repelente a insetos e ação fungicida e bactericida. Ele é tambémutilizado na fabricação de perfumes e cosméticos (BILLERBECK et al., 2001; MUMCUOGLU et al., 2004; REIS et al., 2006; TRONGTOKIT et al., 2005; WONG et al., 2005).
Este trabalho teve por objetivo verificar a variação do teor e composição do óleo essencial de C. nardus, em cinco épocas de colheita, no Estado do Tocantins.

\section{Material e métodos}

O experimento foi instalado na Universidade Federal do Tocantins, Campus de Gurupi, localizado a $11^{\circ} 43^{\prime} 45^{\prime \prime}$ de latitude sul e $49^{\circ} 04^{\prime} 07^{\prime \prime}$ de longitude oeste, com altitude média de $300 \mathrm{~m}$. Segundo o método de Thornthwaite, o clima é do tipo Aw' (clima úmido com moderada deficiência hídrica) (SECRETARIA DO PLANEJAMENTO E MEIO AMBIENTE, 2003). A exsicata, com amostra do material vegetal, foi depositada no herbário da Universidade Federal de Viçosa com o número VIC 30283.

O preparo das mudas foi realizado por divisão de touceiras e o transplante feito no dia 15 de setembro de 2004. No plantio, foi utilizado o espaçamento de $1 \mathrm{~m}$ entre fileiras e $0,5 \mathrm{~m}$ entre covas, plantando-se três perfilhos por cova. Foi utilizada adubação orgânica de $3 \mathrm{~kg}$ de esterco bovino por cova. A análise do solo da área experimental, classificado como latossolo vermelho-amarelo distrófico de textura média, consta na Tabela 1.

Foram feitas coletas para extração do óleo essencial em cinco épocas, a partir de 56 dias após transplante (DAT), em intervalos regulares de 28 dias. Em cada época de colheita, foram retiradas amostras para extração do óleo essencial em triplicata (época $1=56$ DAT; época $2=$ 84 DAT; época $3=112$ DAT; época $4=140$ DAT e época $5=168$ DAT).

O óleo essencial foi obtido por hidrodestilação, a partir de amostras da parte aérea da planta desidratada $(0,02 \mathrm{~kg})$. As amostras foram colocadas em balão de fundo redondo contendo 1 litro de água destilada, que foi acoplado ao clevenger e este a um condensador. Após destilação por 2 horas, foram recolhidos, aproximadamente, 0,4 litro de hidrolato (água + óleo essencial).

O óleo foi extraído da fase aquosa com funil de separação, utilizando o pentano como solvente. Foram realizadas três extrações com $0,05 \mathrm{~L}$ de pentano. As frações orgânicas obtidas foram reunidas e secadas com sulfato de magnésio anidro, filtradas e o solvente foi removido sob pressão reduzida em evaporador rotativo a $40{ }^{\circ} \mathrm{C}$. A massa do óleo essencial obtido foi determinada por pesagem em balança analítica, com precisão de $0,0001 \mathrm{~kg}$.

As amostras de óleo obtidas foram transferidas para frascos de vidro e armazenadas sob atmosfera de nitrogênio em freezer a $-20{ }^{\circ} \mathrm{C}$, até o momento das análises. A identificação dos compostos do óleo essencial 
Tabela 1 - Análise química do solo

\begin{tabular}{|c|c|c|c|c|c|c|c|c|c|}
\hline $\mathrm{PH}$ & $\mathrm{P}$ & $\mathrm{K}$ & $\mathrm{Al}$ & $\mathrm{Ca}$ & $\mathrm{Mg}$ & $\mathrm{H}+\mathrm{Al}$ & CTC & $\mathrm{V}$ & $\mathrm{m}$ \\
\hline $\mathrm{CaCl}_{2}$ & \multicolumn{2}{|c|}{$\mathrm{mg} \mathrm{dm^{-3 }}$} & \multicolumn{5}{|c|}{$\mathrm{cmol}_{\mathrm{c}} \mathrm{dm}^{-3}$} & \multicolumn{2}{|c|}{$\%$} \\
\hline 4,5 & 1,2 & 42 & 0,2 & 0,7 & 0,4 & 2,6 & 3,81 & 31,76 & 1,8 \\
\hline
\end{tabular}

foi realizada por cromatografia gasosa acoplada ao espectrômetro de massas (CG-EM) (CASTRO et al., 2004c; MENUT et al., 1993; OKUNADE, 2002), em equipamento Shimadzu, modelo CG 17A, com detector seletivo de massa, modelo QP 5000. A coluna cromatográfica utilizada foi do tipo capilar de sílica fundida com fase estacionária DB-5, de $0,30 \times 10^{-3} \mathrm{~m}$ de comprimento e $0,25 \times 10^{-3} \mathrm{~m}$ de diâmetro interno, utilizando hélio como gás carreador. As temperaturas foram de $220^{\circ} \mathrm{C}$, no injetor, e $300^{\circ} \mathrm{C}$, no detector. A temperatura do forno foi programada de $60^{\circ} \mathrm{C}$ a $240{ }^{\circ} \mathrm{C}$, com acréscimo de $3^{\circ} \mathrm{C}$ a cada $60 \mathrm{~s}$. A temperatura inicial foi de $60^{\circ} \mathrm{C}$ por $60 \mathrm{~s}$, seguido de um incremento de $3{ }^{\circ} \mathrm{C}$ por $60 \mathrm{~s}$ até atingir $240^{\circ} \mathrm{C}$, sendo mantida constante por $1800 \mathrm{~s}$.

A identificação dos componentes foi feita por comparação dos espectros de massas com os espectros de massas disponíveis no banco de dados do equipamento, com a literatura e pelo índice de Kovat's (ADAMS, 1995; COLLINS, 1997).

A quantificação dos componentes foi realizada utilizando um cromatógrafo a gás com detector de ionização de chama de hidrogênio, em equipamento Shimadzu CG17A. As análises foram realizadas nas mesmas condições descritas para a identificação dos constituintes. Essas análises foram realizadas em triplicatas.

\section{Resultados e discussão}

O cultivo de C. nardus, nas condições edafoclimáticas do Estado do Tocantins, proporcionou uma produtividade de $66,11 \mathrm{t} \mathrm{ha}^{-1}$ de massa fresca e de 25,58 $\mathrm{t} \mathrm{ha}^{-1}$ de massa seca, aos 168 dias após plantio.

Os maiores teores de óleo essencial foram obtidos na segunda época de colheita $(1,10 \%)$ e na última época de colheita $(1,07 \%)$. Na terceira época de colheita foi obtido o menor valor em teor de óleo essencial (0,65\%) (Figura 1).

Na Tabela 2, observa-se que ocorreu variação no número de compostos do óleo essencial do $C$. nardus presentes nas cinco épocas de colheita. Foi obtido, na quinta época de colheita (168 DAT), o maior número de compostos (52) e, na segunda época de colheita (84 DAT), o menor número de compostos (38).

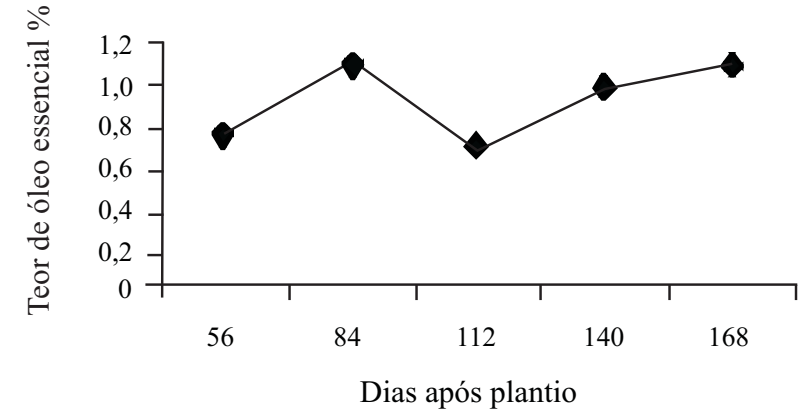

Figura 1 - Teor de óleo essencial de Cymbopogon nardus, em cinco épocas de colheita

Vinte e três compostos químicos foram identificados no óleo essencial do C. nardus, dividos em monoterpenos e sesquiterpenos, mostrados na Tabela 2 e nas Figuras 2 e 3.
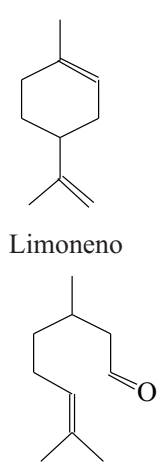

Citronelal<smiles>CC(C)=CCCC(C)=CCO</smiles>

Geraniol



Linalol



Citronelol

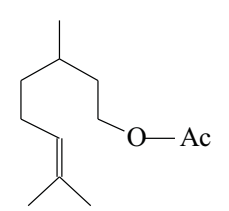

Acetato de citronelol<smiles>C=C(C)C1CC[C@@H](C)CC1O</smiles>

Isopulegol

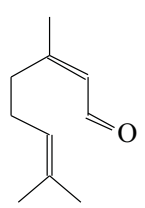

Neral

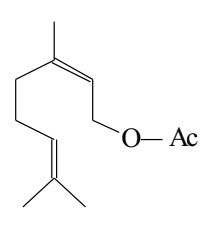

Figura 2 - Fórmulas estruturais dos constituintes monoterpênicos presentes no óleo essencial da parte aérea de Cymbopogon nardus (identificados por cromatografia gasosa acoplada à espectrometria de massa) 
Tabela 2 - Concentração relativa (área \%), obtida por cromatografia gasosa, dos constituintes do óleo essencial da parte aérea de Cymbopogon nardus, em cinco épocas de colheita

\begin{tabular}{|c|c|c|c|c|c|c|}
\hline \multirow[b]{2}{*}{ Compostos } & \multicolumn{5}{|c|}{ Épocas de Colheita } & \multirow[b]{2}{*}{ IK } \\
\hline & Época 1 & Época 2 & Época 3 & Época 4 & Época 5 & \\
\hline $\mathrm{C} 1$ & 0,53 & - & 2,33 & - & - & 1027 \\
\hline $\mathrm{C} 2$ & 0,81 & 1,15 & 1,46 & 0,81 & 0,76 & 1098 \\
\hline $\mathrm{C} 3$ & 0,34 & 0,56 & 0,61 & 0,30 & 0,30 & 1142 \\
\hline $\mathrm{C} 4$ & 4,03 & 3,27 & 3,99 & 1,80 & 2,38 & 1153 \\
\hline $\mathrm{C} 5$ & 10,34 & 17,77 & 17,70 & 18,75 & 19,27 & 1233 \\
\hline C6 & - & 0,25 & 0,20 & 0,16 & 0,13 & 1240 \\
\hline $\mathrm{C} 7$ & 31,63 & 38,40 & 38,30 & 37,70 & 38,18 & 1262 \\
\hline $\mathrm{C} 8$ & 5,73 & 4,02 & 4,71 & - & 1,70 & 1354 \\
\hline $\mathrm{C} 9$ & 9,80 & 4,31 & 4,47 & 1,86 & 1,15 & 1383 \\
\hline $\mathrm{C} 10$ & 1,09 & 0,83 & 0,67 & 1,08 & 1,23 & 1389 \\
\hline $\mathrm{C} 11$ & 0,43 & 0,25 & 0,16 & 0,44 & 0,44 & 1476 \\
\hline $\mathrm{C} 12$ & 0,10 & - & - & 0,10 & 0,09 & 1496 \\
\hline $\mathrm{C} 13$ & 0,42 & 0,30 & 0,23 & 0,46 & 0,54 & 1499 \\
\hline C14 & - & - & 0,17 & 0,24 & 0,22 & 1509 \\
\hline $\mathrm{C} 15$ & 0,58 & 0,38 & 0,29 & 0,39 & 0,37 & 1520 \\
\hline C16 & 11,33 & 8,75 & 8,76 & 10,17 & 10,53 & 1549 \\
\hline $\mathrm{C} 17$ & 2,39 & 1,55 & 1,44 & 3,83 & 3,63 & 1572 \\
\hline $\mathrm{C} 18$ & - & - & - & 0,27 & - & 1578 \\
\hline C19 & 1,92 & 1,20 & 0,96 & 1,94 & 1,67 & 1638 \\
\hline $\mathrm{C} 20$ & 2,04 & 1,57 & 1,42 & 1,67 & 1,60 & 1645 \\
\hline $\mathrm{C} 21$ & 1,38 & - & - & - & - & 1650 \\
\hline $\mathrm{C} 22$ & 1,93 & 2,58 & 2,39 & 2,78 & 2,58 & 1653 \\
\hline $\mathrm{C} 23$ & - & - & 0,17 & - & - & 1711 \\
\hline $\mathrm{NC}$ & 42 & 38 & 43 & 40 & 52 & \\
\hline
\end{tabular}

$\mathrm{C} 1$ = limoneno; $\mathrm{C} 2$ = linalol; $\mathrm{C} 3=$ isopulegol; $\mathrm{C} 4=$ citronelal; $\mathrm{C} 5=$ citronelol; $\mathrm{C} 6=$ neral; $\mathrm{C} 7=$ geraniol $\mathrm{C} 8=$ acetato de citronelol; $\mathrm{C} 9=$ acetato de geraniol; $\mathrm{C} 10$ = beta-elemeno; $\mathrm{C} 11$ = germacreno $\mathrm{D} ; \mathrm{C} 12=$ alfa-muroleno; $\mathrm{C} 13=$ germacreno $\mathrm{A} ; \mathrm{C} 14$ = gama-cadineno; $\mathrm{C} 15=$ delta-cadineno; $\mathrm{C} 16$ = elemol; $\mathrm{C} 17$ = germacreno D-4-ol; C18 = óxido de cariofileno; $\mathrm{C} 19=$ tau-cadinol; $\mathrm{C} 20=$ beta-eudesmol; $\mathrm{C} 21$ = alfa-eudesmol; $\mathrm{C} 22=$ alfa-cadinol; $\mathrm{C} 23$ = farnesol; $\mathrm{NC}=$ número de compostos; $\mathrm{IK}=$ Índice de Kovats

Em todas as épocas de colheita, foi obtida maior concentração relativa de compostos monoterpênicos, em relação aos sesquiterpênicos. Na terceira época de colheita, foi obtida a maior concentração relativa de monoterpenos, $73,77 \%$ (Figura 4). O forte odor do óleo essencial é justificado pela presença dos monoterpenos como componentes majoritários. 


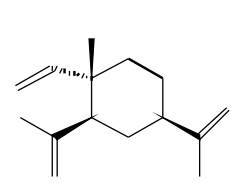

Beta-elemeno<smiles>C=C(C)C1CC=C(C)CCC=C(C)CC1</smiles>

Germacreno A<smiles>C=CC1(C)CCC(C(C)(C)O)CC1C(=C)C</smiles>

Elemol<smiles>CC1=C[C@@H]2[C@H](CC1)[C@@H](O)CC[C@@H]2C(C)C</smiles>

Tau-cadinol<smiles>C=C1C=CC(C(C)C)CCC(C)=CCC1</smiles>

Germacreno D<smiles>C=C1CCC(C(C)C)C2C=C(C)CC[C@H]12</smiles>

Gama-cadineno

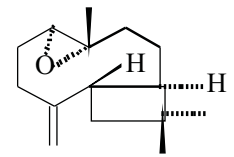

Germacreno D-4-OL Óxido de cariofileno
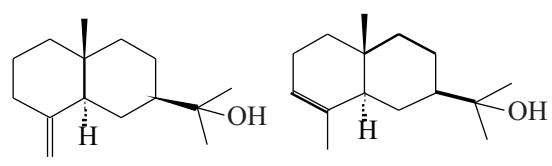

Beta-cadinol<smiles>CC1=CCCC(C)(O)C=CC1C(C)C</smiles><smiles>CC1=C[C@@H]2[C@H](CC1)[C@@H](O)CC[C@@H]2C(C)C</smiles>

Alfa-cadinol

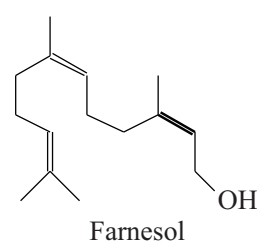

Farnesol
Figura 3 - Fórmulas estruturais dos constituintes sesquiterpênicos presentes no óleo essencial da parte aérea de Cymbopogon nardus (identificados por cromatografia gasosa acoplada à espectrometria de massa)

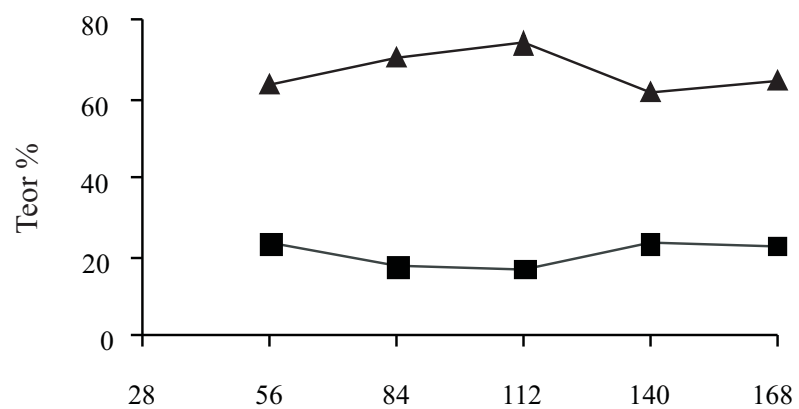

Dias após plantio

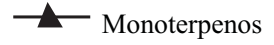

Sesquiterpenos

Figura 4 - Concentração relativa de monoterpenos e sesquiterpenos do óleo essencial de Cymbopogon nardus, em cinco épocas de colheita
Foram identificados três compostos majoritários: o citronelol (monoterpeno), o geraniol (monoterpeno) e o elemol (sesquiterpeno). Em todas as épocas de colheita o geraniol foi o composto predominante que obteve a maior concentração relativa. $\mathrm{Na}$ segunda época de colheita, aos 84 dias após transplante, foi obtida a maior concentração relativa do geraniol $(38,40 \%)$ (Figura 5).

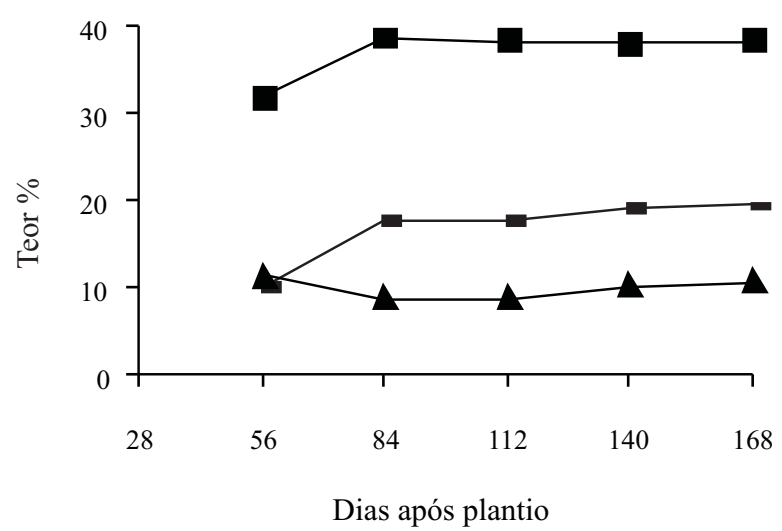

Figura 5 - Concentração relativa dos compostos majoritários do óleo essencial de Cymbopogon nardus: geraniol, citronelol e elemol, em cinco épocas de colheita

Outros trabalhos realizados, que identificaram os constituintes do óleo essencial do C. nardus por CG/EM, encontraram como constituintes do óleo essencial compostos monoterpênicos e sesquiterpênicos. Os constituintes majoritários do óleo essencial foram o geraniol, o citronelol, o citronelal, o elemol, o $(E)$-nerolidol e o beta-cariofileno (CASTRO et al., 2007; MAHALWAL; ALI, 2002).

Resultados semelhantes foram encontrados no trabalho da ação acaricida do óleo essencial de Cymbopogon winterianus, encontrando como constituintes majoritários o citronelal, o geraniol e o citronelol. Os resultados indicaram que o citronelal e o geraniol tiveram uma ação acaricida significativamente mais forte que o citronelol (MARTINS, 2006).

Os compostos monoterpênicos limoneno, citronelal, geraniol e neral atuam na defesa química da planta contra a ação de predadores. Os vapores do citronelal, utilizados por formigas, podem causar irritação suficiente em um predador para fazê-lo desistir de um ataque. O geraniol também possui atividade antiséptica, inibindo o crescimento de fungos e bactérias (MANN, 1995; SIMÕES et al., 2004). 
Martins et al. (2004), analisando o óleo essencial de Cymbopogon citratus extraído das folhas secas e analisado em cromatógrafo gasoso, verificaram que os componentes majoritários do óleo essencial são monoterpenos, justificando o forte odor do óleo essencial. O óleo essencial de Cymbopogon citratus é caracterizado por apresentar citral como componente majoritário na forma de seus dois isômeros: geranial e neral. O citral é utilizado como matéria prima de importantes compostos químicos, denominados iononas, utilizados na perfumaria e na síntese de vitamina A.

Kasali et al. (2001), estudando a composição do óleo essencial de Cymbopogon citratus por meio da técnica de CG/EM, encontraram três constituintes majoritários: o geranial, neral e o mirceno. O geranial e o neral possuem atividade antibacteriana comprovada.

\section{Conclusões}

O teor médio de óleo essencial obtido da parte aérea da planta coletada, considerando as cinco épocas de colheita, foi de $0,90 \%$. A técnica de CG/EM proporcionou a identificação de vinte e três compostos químicos no óleo essencial, entre monoterpenos e sesquiterpenos. Os compostos majoritários do óleo essencial foram o citronelol, o geraniol e o elemol.

A partir dos resultados da análise do teor de óleo essencial, obtido aos 168 dias após plantio, permite-se a projeção de uma produção de $273,71 \mathrm{Kg} \mathrm{ha}^{-1}$ de óleo essencial.

\section{Agradecimento}

Ao Prof. Luiz Cláudio de Almeida Barbosa do Departamento de Química da Universidade Federal de Viçosa, pela colaboração na análise do óleo essencial de Cymbopogon nardus.

Ao Conselho Nacional de Desenvolvimento Científico e Tecnológico $(\mathrm{CNPq})$ e à Secretaria de Ciência e Tecnologia do Estado do Tocantins pelo apoio financeiro.

\section{Referências}

ADAMS, R. P. Identification of essential oil components by gas chromatography/ mass spectroscopy. Ilinois: Allured Publishing Corporation, 1995. 469 p.

BEZERRA, A. M. E. et al. Produção e composição química da macela em função da época de colheita. Horticultura Brasileira, v. 26, n. 01 , p. 26-29, 2008.
BILLERBECK, V. G. et al. Effects of Cymbopogon nardus (L.) $\mathrm{W}$. Watson essential oil on the growth and morphogenesis of Aspergillus niger. Canadian Journal of Microbiology, v. 47, n. 01, p. 9-17, 2001.

BROWN JÚNIOR, K. S. Engenharia ecológica: novas perspectivas de seleção e manejo de plantas medicinais. Acta Amazônica, v. 18, n. 01, p. 291-303, 1988.

CARVALHO FILHO, J. L. S. et al. Influence of the harvesting time, temperature and drying period on basil (Ocimum basilicum L.) essential oil. Revista Brasileira de Farmacognosia, v. 16, n. 01, p. 24-30, 2006.

CASTRO, H. G. et al. Contribuição ao estudo das plantas medicinais: metabólitos secundários. 2. ed. Viçosa: UFV, 2004a. 113 p.

CASTRO, H. G. et al. Crescimento, teor e composição do óleo essencial de Cymbopogon nardus (L.). Revista Brasileira de Plantas Medicinais, v. 09, n. 04, p. 55-61, 2007.

CASTRO, H. G. et al. Divergência genética entre acessos de mentrasto avaliada por características botânico-agronômicas, moleculares e fitoquímicas. Revista Ceres, v. 51, n. 294, p. 227-241, 2004b.

CASTRO, H. G. et al. Rendimento de tanino em dois acessos de carqueja (Baccharis myriocephala D.C.), em diferentes épocas de colheita em Viçosa-MG. Revista Brasileira de Plantas Medicinais, v. 01, n. 02, p. 29-33, 1999.

CASTRO, H. G. et al. Teor e composição do óleo essencial de cinco acessos de mentrasto. Química Nova, v. 27, n. 01, p. $55-57,2004 \mathrm{c}$

COLLINS, H. C.; BRAGA, G. L.; BONATO, P. S. Introdução a métodos cromatográficos. Campinas: UNICAMP, 1997. 279 p.

COSTA, L. C. B. et al. Produção de biomassa e óleo essencial de elixir-paregórico em função do corte das inflorescências e épocas de colheita. Horticultura Brasileira, v. 25, n. 02, p. 175-179, 2007.

KASALI, A. A.; OYEDEJI, A. O.; ASHILOKUN, A. O. Volatile leaf oil constituents of Cymbopogon citratus (DC) Stapf. Flavor and Fragrance Journal, v. 16, n. 05, p. 377-378, 2001.

LEAL, T. C. A. B. et al. Avaliação do efeito da variação estacional e horário de colheita sobre o teor foliar de óleo essencial de capim-cidreira (Cymbopogon citratus (DC) Stapf). Revista Ceres, v. 48, n. 278, p. 445-453, 2001.

LOAYZA, I. et al. Essential oils of Baccharis salicifolia, $B$. latifolia and B. dracunculifolia. Phytochemistry, v. 38, n. 02, p. 381-389, 1995.

MAHALWAL, V. S.; ALI, M. Volatile constituents of Cymbopogon nardus (Linn.) Rendle. Flavor and Fragrance Journal, v. 18, n. 01, p. 73-76, 2002.

MANN, J. Secondary metabolism. 2. ed. Oxford: Clarendon Press, $1995.374 \mathrm{p}$

MARTINS, M. B. G. et al. Caracterização anatômica da folha de Cymbopogon citratus (DC) Stapf (Poaceae) e perfil químico do 
óleo essencial. Revista Brasileira de Plantas Medicinais, v. 06, n. 03, p. 20-29, 2004.

MARTINS, R. M. Estudio "in vitro" de la acción acaricida del aceite esencial de la gramínea citronela de java (Cymbopogon winterianus Jowitt) no carrapato Boophilus microplus. Revista Brasileira de Plantas Medicinais, v. 08, n. 02, p. 71-78, 2006.

MENUT, C. et al. Aromatic plants of tropical central África. Part x chemical composistion of the essential oils of Ageratum houstonianum Mill. and Ageratum conyzoides L. from Cameroom. Flavour and Fragance Journal, v. 08, n. 01, p. 1-4, 1993.

MUMCUOGLU, K. Y. et al. Repellency of citronella for head lice: double-blind randomized trial of efficacy and safety. Israel Medical Association Journal, v. 06, n. 12, p. 756-759, 2004.

OKUNADE, A. D. Ageratum conyzoides L. (Asteraceae). Fitoterapia, v. 73, p. 1-16, 2002.
REIS, G. G. et al. Estudo do efeito da secagem em convecção natural e forçada na composição do óleo essencial da citronela (Cymbopogon nardus). Revista Brasileira de Plantas Medicinais, v. 08, n. 04, p. 47-55, 2006.

SIMÕES, C. M. O. et al. Farmacognosia: da planta ao medicamento. 5. ed. Porto Alegre: UFRGS, 2004. 1102 p.

TOCANTINS. Secretaria do Planejamento e Meio Ambiente. Atlas do Tocantins: subsídios ao planejamento da gestão territorial. 3. ed. Palmas: SEPLAN, 2003. 49 p.

TRONGTOKIT, Y. et al. Comparative repelency of 38 essential oils against mosquito bites. Phytotherapy Research, v. 19, n. 04, p. 303-309, 2005.

WONG, K. K. Y. et al. Citronella as an insect repellent in food packaging. Journal of Agricultural and Food Chemistry, v. 53, n. 11, p. 4633-4636, 2005. 